University of Nebraska - Lincoln

DigitalCommons@University of Nebraska - Lincoln

To Improve the Academy

Professional and Organizational Development

Network in Higher Education

1997

Faculty Development and the Inclusion of Diversity in the College

Classroom: Pedagogical and Curricular Transformation

James A. Anderson

Follow this and additional works at: https://digitalcommons.unl.edu/podimproveacad

Part of the Higher Education Administration Commons

Anderson, James A., "Faculty Development and the Inclusion of Diversity in the College Classroom: Pedagogical and Curricular Transformation" (1997). To Improve the Academy. 373.

https://digitalcommons.unl.edu/podimproveacad/373

This Article is brought to you for free and open access by the Professional and Organizational Development Network in Higher Education at DigitalCommons@University of Nebraska - Lincoln. It has been accepted for inclusion in To Improve the Academy by an authorized administrator of DigitalCommons@University of Nebraska - Lincoln. 
Anderson, J.A., (1997). Faculty development and the inclusion of diversity in the college classroom: Pedagogical and curricular transformation. In D. DeZure (Ed), To Improve the Academy, Vol. 16 (pp. 41-52). Stillwater, OK: New Forums Press and the Profeasional and Organizational Development Network in Higher Education. Key Words: Faculty Development, Faculty Attitudes, Diversity.

\section{Faculty Development and the Inclusion of Diversity in the College Classroom: Pedagogical and Curricular Transformation}

\section{James A. Anderson}

North Carolina State University

Colleges and universities are confronted with a plethora of questions and concerns that are associated with the inclusion and success of diverse student populations. Especially critical is the role that faculty will play in fostering a supportive and effective learning environment which benefits the wide range of racial, cultural, gender, and class groups. Faculty development activities can assist faculty to make their courses more inclusive both in content and in pedagogy. Those who direct teaching excellence and faculty development efforts must be more proactive as they impact faculty attitudes toward diversity.

Within higher education there exists an increased emphasis on the enhancement of undergraduate education across disciplines.' Moreover, special attention has been given to the performance and success of student populations who, in various ways, differ from the traditional 
profile of an entering student. These student populations are often identified as diverse, underrepresented, nontraditional and/or minority. The presence of diverse groups in the traditional college classroom has generated new challenges and tensions, and has resulted in the emergence of a new area of inquiry in our academic institutions. Issues that are associated with student retention, classtoom performance and teaching effectiveness have become increasingly linked to issues of diversity. Banks (1991) suggests that these links evolve in a systematic way by examining the interplay of social and cultural diversity with learning styles, curriculum content, and instructional styles.

Among the new challenges that college instructors face are to understand learning needs and differences among different students, to alter the learning environment when information suggests they should, and to reevaluate their instructional approaches. Valid concerns have been raised about the appropriateness of "teaching for diversity." The implication is that faculty are expected to cater to the needs of isolated student populations while sacrificing rigor and quality, and the needs of majority students. Perhaps a different set of semantics could be utilized to define the emerging relationship between instructors and diverse populations. There exists several truisms, however, which suggest an inevitability to the need to address this relationship in a systematic way. Among the truisms are:

1. Effective teaching cannot be limited to the delivery of information; rather it needs to be based upon a model of how students learn.

2. Effective teachers are those who involve all students in learning how to learn.

3. The generative process of learning is most effective when instructors affirm the presence and validity of diverse learning styles, and maximize the climate or conditions for learning in the classroom.

4. The degree of success for diverse college students is directly tied to the acceptance and willingness of faculty to address issues of diversity in the classroom.

5. There exists ample support for the contention that the effective application of diversity in the classroom benefits all students. 
6. Many aspects of the diversity discussion have always been present in discussions on effective teaching, and these aspects preceded concerns about diverse learners.

Concerning this last point, there has always been the recognition that groups of students, majority and diverse, enter college with variations in: (1) social relational skills, values, and characteristics, (2) information processing orientations and skills, (3) communication patterns, (4) learning styles and strategies, (5) motivational styles, and psychological characteristics (Anderson and Adams, 1992). If we acknowledge that such variations exist within a homogeneous population of traditional college students, then there must be even greater variability in the same classroom as students become increasingly diverse.

Many college instructors are concerned with how the broad range of demographic characteristics impact student learning, faculty-student interactions, and student acceptance of certain instructional approaches. Faculty development activities represent an area of instructional support that in the future must assist faculty in negotiating the often difficult pathways that connect diversity to effective classroom teaching and learning.

I would like to identify several postulates which can help to establish the parameters for a critical discourse about teaching effectiveness and diversity.

\section{Postulate \#1}

The large majority of faculty have not selected a position or identified a camp which limits them to a single, narrow perspective about diversity and effective teaching and learning.

\section{Postulate \#2}

A discussion of diversity with faculty should begin and end with an emphasis on effective teaching and learning outcomes. The diversity concept can permeate the discussion, but it should not be the focal point. 


\section{Postulate \#3}

When discussing diversity with faculty, it is important to demonstrate three things: It coincides with their values; it has academic rigor; and it can provide measurable outcomes.

\section{Postulate \#4}

When discussing diversity with faculty, it is better to provide them with questions and not dictates. Let them identify the critical issues and answers.

\section{Postulate \#5}

It is not as effective to discuss diversifying the curriculum unless we are also willing to discuss a transformation of pedagogy.

\section{Postulate \#6}

The real impact of diversity on teaching may be revealed in terms of what it does for majority populations and how it effects diverse populations.

\section{Postulate \#7}

Faculty development and teaching center efforts need to expand their issues of consideration and broaden their linkages to address effectively issues of diversity.

\section{Traditional Pedagogy and Diverse Learners}

Misconceptions frequently arise when there are discussions about the impact of traditional teaching methods on the learning of diverse students. Some critics of traditional pedagogy contend that it overemphasizes mastery of the content, and it primarily rewards learning that is associated with rational, objective approaches which are more characteristic of traditional white male learners. Belenky, Clinchy, Goldberger, and Tarule (1986) suggest that traditional pedagogy rewards separate, rather than connected, knowing whereby students learn disciplinary content and methods of analysis on the terms of the dominant cultures. Students do not, however, experience the personal 
emergence that comes from connecting their education to their own experiences, or from raising and answering their own questions and concerns from their own frame of reference. Maher and Tetreault (1994), for example, studied 18 teachers in six different college environments and elaborate upon the way different teaching practices impact different types of learners - in particular women and minorities. They identify four themes which are salient in discussions of traditional pedagogy and diversity. The themes are:

Mastery has traditionally meant the goal of rational comprehension of material on the instructor's terms. Diverse students may seek mastery on their own terms and with others.

Voice connotes the ways in which students and instructors articulate their own sense of their experiences and their learning.

Authority refers to the fact that teachers and students stand in a hierarchical relationship to knowledge and scholarly expertise.

Positionality encompasses how the validity of knowledge comes from an acknowledgment of the knower's specific position in any context as defined by certain variables like race, class, age, skill-level, economic status, etc.

Other authors focus on the specific communication patterns which occur between instructors and students. Sanders and Wiseman (1994) suggest that immediacy is clearly linked to teaching effectiveness, especially with student populations that are diverse by race and culture. Immediacy is defined as that communication which enhances closeness to another. It reflects a positive attitude on the part of the sender toward the receiver and is linked to instructor approachability, trust, warmth, and closeness. Anderson (1979) found that immediacy positively influenced student affect toward teacher communication, course content, the course in general, and the course instructor.

It may be the case that diverse student populations respond positively to a pedagogy which exhibits some degree of immediacy at least in student perceptions. One way to test this hypothesis is to examine the type of instruction which occurs in programs in which diverse students exhibit both academic success and satisfaction. Anderson (1994) reviewed several successful programs in science and math for students of color. These programs existed across different types of two-year and four-year institutions and seem to address both issues of 
immediacy and the aforementioned themes of mastery, voice, authority, and positionality. Figure 1 outlines the instructional characteristics.

It appears that such programs rely upon a combination of traditional and nontraditional pedagogy and connect well with the preferred learning styles of students of color.

The following represent the types of scenarios which have become quite common on our campuses. They also represent areas of impact which could fall under the purview of faculty and administrators who make decisions about the presence and impact of diversity. The voice which, historically, has not been as resonant but which will be called upon more in the future for advice and insight is that of the faculty development specialist.

Figure 1

Characteristics of Effective Science-Math Instruction

The teacher:

- fosters a sense of community grounded on the shared experience of doing serious work;

- utilizes student feedback periodically to assess teaching ability;

- individualizes and personalizes classroom presentations when necessary;

- provides students with hands-on activities and involvement;

- provides appropriate feedback when students experience conceptual difficulties;

- acknowledges developmental level of students and teaches to that level;

- varies instructional method;

- encourages students to express their reasoning process in their own words (especially futility);

- guides students in learning how to frame new questions;

- guides students in the use of alternate learning strategies; and

- shows connections between isolated pieces of information. 


\section{Scenario 1}

The Provost at a large urban institution wants his/her faculty to respond to the increased diversity among student populations. Students have complained increasingly that faculty cannot relate to them in the classroom. The Provost wants to provide incentives to the faculty to provide more effective instruction for diverse populations. $\mathrm{He} /$ she wants to utilize faculty development as the vehicle of implementation. What suggestions should be made to the Provost?

\section{Scenario 2}

At an eastern community college, a non-traditional adult student has experienced discomfort in most of his/her classes. While he/she listens to the rapid-rate responses of the 18-22 year-old students, he/she experiences difficulty with the abstract nature of the course content and the examples that the students use. The non-traditional student also has anxieties about his/her readiness for college. How can the instructor better meet the needs of this student?

\section{Scenario 3}

At the college of science and mathematics at a midwestern university, technology in the classroom has become the new mantra. Decisions about hardware and software do not follow a consistent pattern. High performance and well-skilled students exhibit learning preferences which match the instructional styles of the highly analytical faculty. Average and less skilled students are not yet at the level of analytical excellence which would facilitate their success. Their technology needs are different, and they prefer a different mode of classroom instruction. What can be done for them?

\section{Curriculum Issues and Diversity}

Among the institutions which have successfully negotiated an agreement on curriculum infusion and transformation, certain things were in place or have occurred which facilitated the faculty's acceptance of an alteration in the traditional curriculum. First of all, an institutional dialogue has occurred which has established organiza- 
tional priorities and definitions. Among the questions which have been addressed are:

- What does it mean to diversify the curriculum at this institution?

- Does such a diversification connect to the mission and vision of the institution?

- What are the benefits to students and to the faculty of an inclusive curriculum?

- Can the institution use existing processes and structures to transform the curriculum or is it necessary to develop new ones?

- How does the implementation of a transformed curriculum negotiate the structural or political barriers which can inhibit its development?

Faculty development specialists can assume the critical role of leading or, at least, participating in the discussion about an enhanced curriculum. They can promote a discourse which maintains a focus on academic rigor and faculty values. They can help to mollify the anxieties of faculty and administrators who fear the challenge to tradition, and who are too myopic to foresee the enormous benefit associated with connecting, in new ways, the curriculum to diversity.

The character of an institution and its faculty will dictate how and how much diversity can and will affect the curriculum. Clarity of purpose is absolutely necessary in the beginning stages of this conversation. In the early stages of the dialogue, if political considerations dominate, it can be difficult to recenter the discussions. On the other hand, a rational and tempered approach which highlights the benefits and positive outcomes associated with curriculum transformation can have a neutralizing effect.

Historically, faculty development specialists and teaching center directors generally have not waded into the political consternation over nontraditional applications to the traditional curriculum. One of the major reasons that this has occurred is because pedagogical change is not always seen as a link to curricular change, especially when the latter focuses primarily on discipline-related content. The transformed curriculum, however, not only involves an expansion of content and scholarship but also the concomitant attention which must be given to changes in students' cognitive frameworks. Those changes occur, 
most effectively, when there is symmetry across teaching, learning and curricular outcomes.

Below are two examples of the purpose of curriculum expansion which could be offered as guideposts for faculty discussions. The first set are politically neutral and tend to overlap with what are often seen as general education or core curriculum goals. The second set are often attributed to those who represent the forgotten or underrepresented voice in academia, and they often become the centerpiece of a political tug-of-war. See Figure 2, below.

Curriculum infusion would appear to be a more effective activity when it is viewed as a curricular and pedagogical activity. The intersection of the two activities can produce outcomes which impact academic content, student learning and cognitive development, stu-

\section{Figure 2 \\ Purpose of Curriculum Expansion Associated with Diversity}

\section{Neutral}

1. Introduce new content and scholarship.

2. Expand and clarify our view of the world.

3. Connect academic disciplines.

4. Create new scholarly perspectives from which we can make judgments.

5. Examine the overlap of the fundamental questions raised across new dimensions.

Politically Charged

1. Historicize and politicize.

2. Connect social categories.

3. Destandardize the notion that the universal baseline for experiences, interests, and characteristics is white and male.

4. Move away from dichotomous and oppositional framing of one dimension (male/female, rich/poor, traditional/nontraditional).

5. Recenter groups with different social positions and positions of power. 
dent classroom interactions and the identities of both faculty and students. Figure 3 compares the movement from a traditional to a transformed curriculum.

Many institutions attempt to identify a single particular area of emphasis concerning diversity, thus limiting the scope of activities from which faculty may choose. The following represent an array of outcome statements which can serve as a menu for faculty involvement.

- To facilitate the development of students' critical thinking skills such that they are able to appreciate multiple realities and perspectives, especially as they emanate from persons who are different from them.

\section{Figure 3}

Transformation as a Curricular and Pedagogical Activity ${ }^{1}$

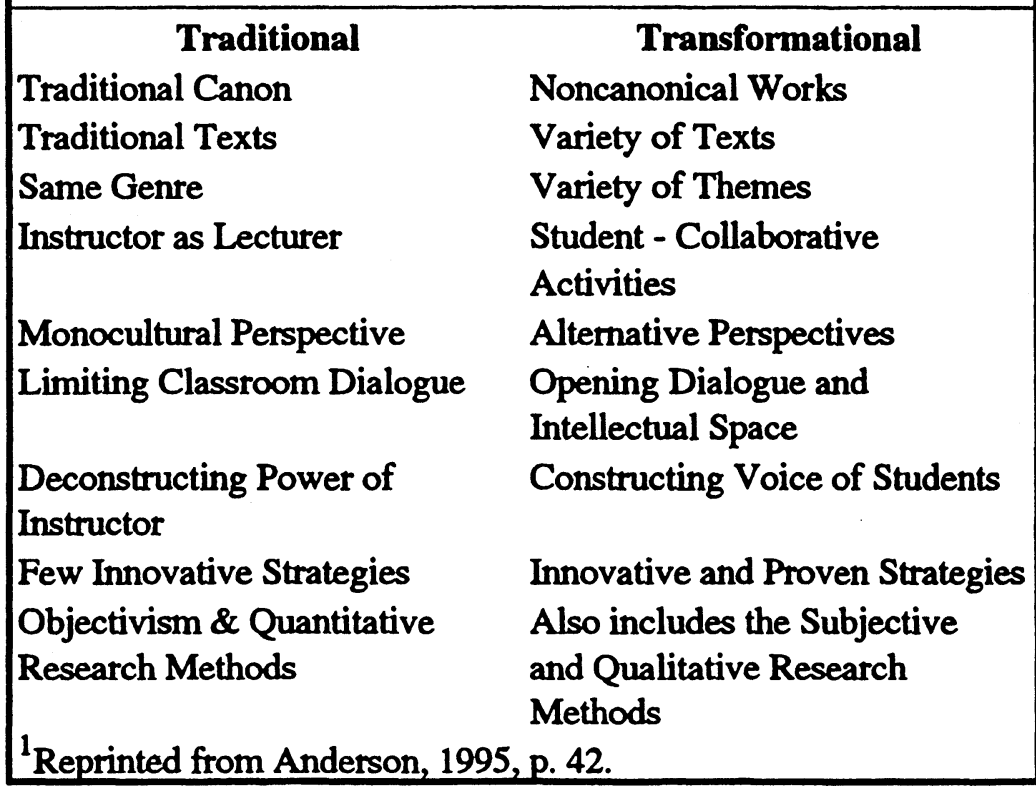


- To encourage the development of questioning and probing skills which allow for an objective and increasingly more sophisticated analysis of the varied dimensions of diversity.

- To promote the classroom as an arena of equity in which students exhibit an appreciation for difference and indicate a security with the exploration of tough questions.

- To incorporate student support activities and teaching/learning activities into a total learning community.

- To understand the fundamental relationship between effective teaching, learning outcomes and the diversity among different student populations.

- To identify the student learning outcomes and associated strategies that instructors should expect from the application of diversity in the classroom.

- To identify instructional strategies that facilitate the self-evaluation of student learning for traditional and non-traditional outcomes.

- To examine the relationship among instructional styles and varied student learning styles.

- To evaluate the relationship between student support service activities, faculty development efforts and classroom outcomes, especially as they pertain to: (1) instructional approaches and (2) the classroom environment.

If we are able to convince faculty that the incorporation of diversity into classroom considerations can maximize student performance and does not threaten what faculty value, then there is a greater chance that it will be embraced. There is no need to reinvent the wheel because there are effective models and research evidence which we can examine.

Those who have oversight for faculty development can play a vital role in fostering a positive intersection among teaching, learning, curriculum development and diversity.

\section{References}

Anderson, J. A. (1995). Merging effective models of diversity with teaching and learning and the curriculum. Raleigh, NC: James Anderson. 
Anderson, J. A. (1994). Examining teaching styles and student learning in science and math classrooms. In M. Atwater (Ed.), Multicultural Education: Inclusion of All (pp. 93-105). Athens, GA: The University of Georgia.

Anderson, J. A. (1979). Teacher immediacy as a predictor of teaching effectiveness. In D. Nimmo (Ed.), Communication Yearbook, Vol. 3 (pp. 543-559). New Brunswick, NJ: Transaction Books.

Anderson, J. A., \& Adams, M. (1992). Acknowledging the Leaming Styles of Diverse Populations: Implications for the College Classroom. In N. Chism \& L. Border (Eds.), Teaching for Diversity (New Directions for Teaching and Learning No. 49) (pp. 19-33). San Francisco: Jossey-Bass.

Banks, J. (1991). Teaching Assistants and Cultural Diversity. In J. Nyquist (Ed.), Preparing the Professoriate of Tomorrow to Teach (pp. 80-86). Dubuque, IA: Kendall/Hunt.

Belenky, M. F., Clinchy, B. M., Goldberger, N. R., \& Tarule, J. M. (1986). Women's Ways of Knowing: The Development of Self, Body, and Mind. New York: Basic Books

Maher, F., \& Tetreault, M.(1994). Inside feminist classrooms: An ethnographic approach. In K. Feldman \& M. B. Paulsen (Eds.), Teaching and Learning in the College Classroom (pp. 227-240). Needham Heights, MA: Ginn Press.

Sanders, J. A., \& Wiseman, R. L. (1994). The effects of verbal and nonverbal teacher immediacy on perceived cognitive, affective, and behavioral learning in the multicultural classroom. In K. Feldman \& M.B. Paulsen (Eds.), Teaching and Learning in the College Classroom (pp. 623-638). Needham Heights, MA: Ginn Press.

\section{Contact: \\ James A. Anderson \\ North Carolina State University \\ Box 7105, B26 Nelson Hall \\ Raleigh, NC 27695-7105 \\ (919) 515-3037}

James Anderson is Vice Provost and Dean of Undergraduate Studies and Professor of Counselor Education at North Carolina State University. He supports teaching excellence initiatives, faculty development, curriculum assessment, and First Year College at North Carolina. State. He has been selected as an American Council on Education Fellow and Danforth Fellow. He has presented extensive workshops at over $\mathbf{2 0 0}$ conferences, universities, and colleges on topics such as retention issues, enhancing faculty instructional competency; facilitating student learning styles/strategies, the infusion of diversity throughout the curriculum and the institution, and critical thinking for diverse populations. He obtained a B.S. degree in psychology from Villanova University and Ph.D. in psychology from Cornell University. 